Abstracta Iranica Abstracta Iranica

Revue bibliographique pour le domaine irano-aryen

Volume 28 | 2007

Comptes rendus des publications de 2005

\title{
Transoxiana. History and culture. Tashkent, Institut Otkrytoe Obščestvo, 2004, 442 p. dont 23 pl. h.-t.
}

\section{Frantz Grenet}

\section{(2) OpenEdition}

1 Journals

\section{Édition électronique}

URL : http://journals.openedition.org/abstractairanica/14902

DOI : 10.4000/abstractairanica.14902

ISSN : 1961-960X

Éditeur :

CNRS (UMR 7528 Mondes iraniens et indiens), Éditions de l'IFRI

\section{Édition imprimée}

Date de publication : 15 mai 2007

ISSN : 0240-8910

\section{Référence électronique}

Frantz Grenet, «Transoxiana. History and culture. Tashkent, Institut Otkrytoe Obščestvo, 2004, 442 p. dont 23 pl. h.-t. », Abstracta Iranica [En ligne], Volume 28| 2007, document 57, mis en ligne le 18 septembre 2007, consulté le 25 septembre 2020. URL : http://journals.openedition.org/ abstractairanica/14902 ; DOI : https://doi.org/10.4000/abstractairanica.14902

Ce document a été généré automatiquement le 25 septembre 2020.

Tous droits réservés 


\section{Transoxiana. History and culture. Tashkent, Institut Otkrytoe Obščestvo, 2004, 442 p. dont 23 pl. h.-t.}

Frantz Grenet

1 Recueil de Mélanges offerts au grand archéologue Èduar Rtveladze, académicien de l'Ouzbékistan, dont la bibliographie est donnée pp. 387-408. Les articles sont pour la plupart en russe, quelques-uns en ouzbek et en anglais. La gamme des sujets traités par les 59 articles est très vaste, reflétant les intérêts de È. Rtveladze et aussi son affiliation institutionnelle à l'Institut d'Histoire de l'Art de Tachkent: archéologie, histoire ancienne et médiévale, numismatique et épigraphie, architecture et urbanisme, histoire de la religion, musicologie, histoire contemporaine et historiographie, tout ceci brossant un panorama très complet de l'état actuel de ces champs de recherche en Ouzbékistan. Le nombre limité des planches d'illustration et le petit format des reproductions font que les articles d'archéologie ne peuvent guère présenter d'éléments de démonstration. Par ailleurs on peut regretter que presque aucune place ne soit réservée aux missions étrangères à l'œuvre en Ouzbékistan depuis 1989 (même si leurs participants se trouvent cités pour leurs travaux personnels) : on ne relève que deux articles (S. Stride et L. Sverčkov sur la découverte de sites de l'Age du Bronze près de Denau, Š. Raxmanov et C. Rapin sur les « Portes de Fer »).

Dans les domaines des études anciennes et médiévales, un relevé nécessairement subjectif dégage les articles suivants, pour leur pertinence ou leur production de données nouvelles (je traduis les titres): K. Abdullaev, «Les statues royales dans la sculpture kouchane " (argumente de manière convaincante une restitution des statues de Xalčajan et de Mathura comme tenant des rameaux) ; N. Avanesovna, «L'écriture en objets de la Bactriane préhistorique " (étude de la sémantique des dépôts funéraires à statuettes de Buston); T. Beljaeva, «Nurtepa - Kyropolis (histoire de la recherche)» (étude de sites antiques de l'Ustrushana, intéressant en particulier pour la mise en 
évidence à Mugtepa d'un temple achéménide ancien, voire pré-achéménide, juché sur une plate-forme à degrés (restitution p.413), dont on a maintenant un parallèle achéménide à Koktepe); S. Bolelov, «La question de la périodisation de l'étape ancienne de l'histoire du Khorezm ancien " (révision de la chronologie admise, en fonction des fouilles de Xumbuztepa); O.Papakhristu, T. Rehren, "Towards a reconstruction of the Ferghana process of Medieval crucible steel smelting " (la vraie naissance de l'acier dit « damasquiné » aurait eu lieu au Ferghana à partir du début du $\mathrm{IX}^{\mathrm{e}} \mathrm{s}$.) ; C. Benjamin, "The location of Janshi", et M. Tezcan, "The conquest of Sogdiana and Bactria by the nomads and the Asiani » (souffrent de la comparaison avec F. Thierry, "Yuezhi et Kouchans. Pièges et dangers des sources chinoises ", in: O. Bopearachchi et M.-F. Boussac (eds.), Afghanistan, ancien carrefour entre l'Est et l'Ouest, Turnhout, 2005, autrement plus précis dans la discussion des sources); M. Filanovič, «La question de l'art militaire dans les États du haut Moyen Age en Asie centrale»; V. Livšic, "Les Sogdiens souhaitent 160 ans à 'Alim-khān 'Abbās" (une inscription sogdienne sur jarre trouvée à Ak-tobe au Kazakhstan méridional comporte une formule de vœu à un personnage portant un nom musulman de type abbasside, sans doute un chef Qarluq islamisé du IX ${ }^{e}$ s. ; elle fournit un mot nouveau, $y w \delta t^{\prime} k$ « jarre »; à noter, pour rétablir la compréhension de l'article, que ā est systématiquement imprimé B); A. Najmark, « À propos de la datation des monnaies d'Axurpat, roi de Kesh » (donnent la forme kšy'n'k « keshien "; grâce aux sources chinoises ce souverain est datable dans la période 722-738; cet article discute aussi certaines questions relatives à la chronologie des souverains de Samarkand).

INDEX

Thèmes : 3.1. Est de l'Iran

\section{AUTEURS}

FRANTZ GRENET

CNRS - EPHE - Paris 